Dossiê Especial: Formação Docente, Tecnologias Digitais e Educação Crítica.

ROCHA; HIBARINO e AZZARI (orgs.)

Revista X, vol.2, 2015

\title{
ENTRE LETRAMENTOS E MULTILETRAMENTOS: CONTRIBUIÇÕES TEÓRICAS PARA UM ENSINO CRÍTICO DE LÍNGUA INGLESA
}

\author{
Between Literacies and Multiliteracies: Theoretical Implications For A Critical \\ English Language Teaching
}

Guilherme Jotto KAWACHI, CEL-UNICAMP ${ }^{1}$

\begin{abstract}
RESUMO: O objetivo deste artigo é propor reflexões em torno do conceito de letramentos e multiletramentos focalizando suas diversas (re)interpretações ao longo dos anos e possíveis contribuições dessas teorizações para o ensino de inglês como língua estrangeira. Assim, este é um trabalho de natureza majoritariamente teórica. Partindo de uma visão discursiva de língua (GEE, 1999; FAIRCLOUGH, 2010), as discussões aqui privilegiadas estão centradas nas ressignificações da noção de letramento em face de mudanças sociais, culturais, tecnológicas e epistemológicas que tem abalado as maneiras como entendemos e usamos línguas e linguagens em décadas recentes, levando à ideia de multiletramentos (COPE; KALANTZIS, 2000; 2013), letramentos múltiplos, críticos e multissemióticos (ROJO, 2009; 2013). A proposta, portanto, é problematizar essas compreensões teóricas e ponderar sobre seus desdobramentos para práticas pedagógicas em língua inglesa, considerando, nesse cenário, a necessidade de fomentarmos, também, discussões sobre questões de criticidade e interculturalidade em um ensino de natureza mais marcadamente formativa, crítica e transformadora.
\end{abstract}

PALAVRAS-CHAVE: ensino de língua inglesa; letramentos; multiletramentos; ensino crítico

ABSTRACT: The purpose of this paper is to raise discussions about the concepts of literacy and multiliteracies, focusing on their diverse (re)interpretations throughout the years, and the possible contributions of such theories for the teaching of English as a Foreign Language (EFL). Therefore, this is mainly a theory-based paper. The discussions presented here stem from a discursive view of language (GEE, 1999; FAIRCLOUGH, 2010) and are centered on the various developments that the theories of literacy have gone through in face of social, cultural technological, and epistemological changes in past years, which have also impacted how we understand and use languages, leading to the ideas of multiliteracies (COPE; KALANTZIS, 2000; 2013) and multiple, critical and multissemiotic literacies (ROJO, 2009; 2013). The point, thus, is to discuss such theories and to reflect about their implications to EFL teaching, considering the need to foment debates on issues of critical thinking as well as interculturality in EFL classes.

KEY-WORDS: English Language Teaching; literacies; multiliteracies; critical teaching

\footnotetext{
${ }^{1}$ Doutor em Linguística Aplicada pelo IEL/UNICAMP. guilhermekawachi@gmail.com
} 


\section{Dossiê Especial: Formação Docente, Tecnologias Digitais e Educação Crítica. \\ ROCHA; HIBARINO e AZZARI (orgs.) \\ Revista X, vol.2, 2015}

\section{INTRODUÇÃO}

O processo de reflexão crítica sobre fatores que permeiam o ensino e a aprendizagem em salas de aulas diversas constitui uma atividade recorrente no cotidiano de qualquer professor. Ainda que nem sempre de maneiras explícitas ou sistemáticas, estamos frequentemente envoltos aos acontecimentos da sala de aula, buscando novas maneiras de compreender os problemas que ali emergem e que nos levam a procurar subsídios teóricos, metodológicos e práticos que possam fomentar compreensões acerca de nossas práticas.

Como docente de Língua Inglesa (LI), foi esse processo que motivou o desenvolvimento de minha pesquisa de doutorado, na qual investiguei discursos e representações interculturais de alunos de inglês em um contexto específico do Ensino Superior. Nesse estudo, ainda que os dados empíricos tenham sido o objeto de análise, tornou-se muito importante, no decorrer da pesquisa, aprofundar reflexões sobre alguns pilares teóricos que orientavam o ensino de LI no contexto focalizado ${ }^{2}$. Diante das especificidades de espaço e tempo deste artigo, opto, aqui, por discutir sobre alguns desses pilares, ao mesmo tempo em que procuro problematizar os benefícios, dificuldades e efeitos de algumas concepções teóricas que embasam práticas pedagógicas em LI em muitos contextos no Brasil e no mundo.

Para tanto, é importante pensar em todas as mudanças e reconfigurações sociais, econômicas, culturais e políticas (e em vários outros âmbitos) pelas quais temos passado, e que impactam, de modos complexos, a maneira como nos comunicamos; como entendemos e usamos uma língua; como construímos, reconstruímos e negociamos sentido em uma língua, especialmente em língua estrangeira.

Como estudiosos da linguagem em um campo aplicado, problematizar conceitos é parte fundamental para a busca por melhores compreensões e caminhos acerca do trabalho com língua, tanto em termos teóricos como práticos. Além disso, revisitar conceitos nos permite examinar criticamente práticas pedagógicas sustentadas por premissas tradicionais que, muitas vezes, ainda imperam na atualidade e, ao mesmo tempo, questionar noções que não parecem favorecer práticas educacionais mais justas, éticas e críticas (ROJO, 2009; MONTE-MÓR, 2012; 2013; ROCHA, 2012).

\footnotetext{
${ }^{2}$ Para mais detalhes sobre a pesquisa, ver Kawachi (2015).
} 


\section{Dossiê Especial: Formação Docente, Tecnologias Digitais e Educação Crítica. ROCHA; HIBARINO e AZZARI (orgs.) \\ Revista X, vol.2, 2015}

Proponho, portanto, neste trabalho, discussões em torno de algumas compreensões sobre as ideias de letramentos e multiletramentos, que representam, a meu ver, um norte teórico e prático pertinente para o ensino de LI que busque se materializar crítico. Assim, ao defender uma educação emancipadora (FREIRE, 1996) e crítica, espero que o debate que pretendo sugerir possa conduzir o leitor mais ao questionamento de questões linguísticas, culturais e educacionais do que ao encontro de certezas - uma das premissas de uma Linguística Aplicada comprometida ética e politicamente com transformações sociais, como aponta Fochzato (2010).

\section{LETRAMENTOS: ALGUMAS CONSIDERAÇÕES CONCEITUAIS}

Ainda que não tenha por objetivo, com essas considerações teóricas, fazer um resgate histórico detalhado e aprofundado acerca do surgimento do termo "letramento", julgo pertinente colocar em discussão as visões de alguns autores acerca do conceito, à luz de produções teórico-pedagógicas principalmente da Linguística Aplicada e Educação, destacando seus diferentes sentidos e contrapondo as significações atribuídas a esse construto e às suas variantes, focalizando a transição das ideias associadas a "letramento" para as teorias de "multiletramentos" ou "letramentos múltiplos". Estes conceitos, por sua vez, são abordados com mais ênfase por se pautarem em uma visão de língua como fator social e discursivo, impulsionando discussões sobre educação, multimodalidade (COPE, KALANZTIS, 2000; 2013; KRESS, 2000), letramentos críticos (LUKE, 2014), entre outros aspectos que têm potencial para colocar em suspenso problemas sociais e culturais que não podem ser ignorados em um ensino voltado para a interculturalidade (MAHER, 2007; KAWACHI, 2015) e criticidade.

Posto isso, parece fazer sentido partir do debate acerca das noções de "letramentos" e "alfabetização". A associação entre as duas construções prevaleceu por muitos anos, possivelmente como reflexo do sentido mais comum da palavra em inglês, "literacy", geralmente significando "alfabetização".

Kleiman (1995, p. 15) esclarece que os estudos do letramento começam a ser desenvolvidos no meio acadêmico no Brasil para estabelecer, em definitivo, as diferenças entre a ideia de "alfabetização" e "letramento" que, segundo a autora, são centrados na investigação dos "impactos sociais da escrita". Em contrapartida, a noção de "alfabetização" está ligada ao ensino da leitura e da escrita por meio do 


\section{Dossiê Especial: Formação Docente, Tecnologias Digitais e Educação Crítica. ROCHA; HIBARINO e AZZARI (orgs.) \\ Revista X, vol.2, 2015}

fortalecimento de capacidades para que essas práticas - leitura e escrita - possam se concretizar. Alfabetismo, nessa perspectiva, pode ser entendido como "o estado ou condição de quem sabe ler e escrever" (SOARES, 2003 [1995], p. 29, apud ROJO, 2009, p. 44). Trata-se, portanto, de um conceito muitas vezes entendido sob perspectivas cognitivas e individuais, como sugere Rojo (2009), diferentemente da ideia de "letramentos" que implica construção social de sentidos por meio da leitura e escrita.

É válido frisar que, como afirma Kleiman (2005, p. 9), "Letramento não é alfabetização, mas a inclui", caracterizando-se como apenas uma das práticas de letramento que são comuns aos contextos escolares. Isso significa que os dois conceitos têm relações semânticas, porém não são equivalentes. Assim, na perspectiva defendida aqui, restringir letramento à ideia de alfabetização seria uma redução problemática, porque letramento é um conceito mais amplo que pressupõe engajamento social por meio de práticas de leitura e escrita que promovam interação, crítica, reflexão e ação. Refere-se, portanto, a uma concepção mais complexa do que a ideia (muitas vezes rasa) de leitura como decodificação ou recuperação de sentidos - o que, argumento, seria incongruente com o aluno que se deseja educar atualmente, ativo e protagonista.

A diferenciação desses dois conceitos em inglês é geralmente apontada pelo uso do singular ("literacy" / alfabetização) em contraposição ao plural ("literacies" / letramentos). Nesse ponto, assim como destaca Kleiman (1995), o termo "literacies" é mais empregado quando o objetivo é discutir a natureza sociocultural da escrita. $\mathrm{O}$ caráter plural do conceito de "letramentos" é reconhecido e defendido por outros autores (COPE; KALANTZIS, 2000; 2013; JENKINS, 2009; KALANTZIS; COPE，2012; KNOBEL; LANKSHEAR, 2011; PENNYCOOK, 2012) cujas perspectivas se aproximam com base no raciocínio de que o termo no plural revela que as práticas de uso da escrita para ação e atuação em contextos sociais amplos não são singulares: são sempre constituídas por múltiplos elementos.

Assim, ao compreender "letramentos" como "elementos construídos socialmente e constitutivos de práticas humanas mais amplas", Knobel e Lankshear (2011, p. 76) associam as ações e os acontecimentos que vivenciamos diariamente aos textos presentes em nossas interações. Nesse sentido, o nosso contato constante com diversas formas de linguagem, discursos e textos contribui para "delinear práticas, processos, crenças e atitudes amplas" (KNOBEL; LANKSHEAR, 2011, p. 76) em um processo que é sempre dialético. 


\section{Dossiê Especial: Formação Docente, Tecnologias Digitais e Educação Crítica. ROCHA; HIBARINO e AZZARI (orgs.) \\ Revista X, vol.2, 2015}

Na mesma direção, Kalantzis e Cope (2012, p. 13) apontam que a transição da perspectiva de letramento como sinônimo de alfabetização para seu sentido plural, englobando a natureza sociocultural da escrita, é inevitável e necessária para a educação de alunos preparados para lidar com as demandas (sociais e tecnológicas) de comunicação no século 21. Os autores enfatizam, ainda, que uma concepção plural do conceito é mais apropriada para a busca por encaminhamentos teóricos e práticos, na sala de aula, visando a participação social do aluno em contextos marcados por diferenças culturais, sociais, socioeconômicas, de gênero e muitas outras.

Portanto, em meio à transição de compreensões tradicionais de alfabetização e alfabetismo para noções situadas do conceito de letramentos, entendo, ao lado de Rojo (2009), que essa construção deve ser observada sempre com um foco sociológico e cultural - porque os sentidos de "ser letrado" variam de acordo com situações, contextos sociais e culturais. Uma definição pertinente, portanto, seria uma que concebe letramentos como

usos e práticas sociais de linguagem que envolvem a escrita de uma ou outra maneira, sejam eles valorizados ou não valorizados, locais ou globais, recobrindo contextos sociais diversos (família, igreja, trabalho, mídias, escola, etc.), numa perspectiva sociológica, antropológica e cultural (ROJO, 2009, p. 98)

Destaco a menção da autora às práticas de letramento cotidianas, que ocorrem na igreja, no trabalho, em casa, isto é, em situações de comunicação e interação cotidianas que são, muitas vezes, desconsideradas nas práticas de letramentos privilegiadas nas escolas. Nesse sentido, uma concepção mais abrangente do conceito é necessária para a busca por encaminhamentos frente ao descompasso entre o que se ensina na escola e o universo do aluno, em vistas à conciliação entre a prática acadêmica e prática social (MONTE MÓR, 2012, p. 188). Além disso, uma compreensão de letramentos mais plural me parece compatível com as múltiplas configurações linguísticas, identitárias e culturais que vivenciamos atualmente.

Alinho-me ao dizer de Kleiman (2005, p. 21) no que concerne à interligação do conceito de letramentos às mudanças sociais e tecnológicas, que evidenciam os desenvolvimentos da escrita em meio a uma série de acontecimentos, como, por exemplo, o surgimento da Internet e de outras tecnologias de comunicação que alteraram significativamente a maneira como lidamos com a escrita e suas diversas 


\section{Dossiê Especial: Formação Docente, Tecnologias Digitais e Educação Crítica. ROCHA; HIBARINO e AZZARI (orgs.) \\ Revista X, vol.2, 2015}

formas de produção e compreensão de sentidos. Essa maneira de compreender o conceito de letramentos contempla as mudanças que a sociedade vem vivendo e situa as práticas de escrita e leitura em um contex to sociocultural mais abrangente.

Em um âmbito prático, essa visão do conceito pode contribuir para auxiliar professores que, se julgarem pertinente, tenham o objetivo de investigar quais letramentos são privilegiados e efetivamente desenvolvidos por seus alunos, em suas mais diversas salas de aula. Isso implicaria, também, pensarmos se estamos oferecendo a esses estudantes oportunidades de práticas de linguagem que lhes serão úteis para suas atuações em esferas pessoais, do trabalho, educacionais (entre outras), ou se estamos insistindo em concepções de língua e ensino demasiadamente conservadoras e que, possivelmente, se distanciam das configurações epistemológicas de um mundo em constante mudança.

Assim, a ideia de letramentos que embasa o debate aqui proposto está intimamente ligada ao engajamento dos aprendizes, à concepção de um aluno questionador que, tanto na sala de aula como fora dela, é mais do que um receptor de conhecimento; é parte essencial da construção de sentidos por meio de (e em) língua inglesa. Nessa conjuntura, o que se espera de um aluno inserido em um ensino calcado nas teorias dos letramentos (e multiletramentos, letramentos críticos) vai além de competências de leitura e escrita de textos de maneira mecânica, por exemplo.

Essas práticas estão associadas, na visão de Knobel e Lankshear (2011) ao conceito de "letramento funcional". Os autores explicam que políticas direcionadas à noção de funcionalidade para a leitura e escrita surgiram nos Estados Unidos e Reino Unido em 1969 e 1973, respectivamente. As publicações governamentais oficiais da época caracterizavam a incapacidade de ler e escrever como obstáculos substanciais aos cidadãos. Para superá-los, as políticas advogavam em favor de práticas que possibilitassem aos indivíduos ter comando das habilidades escritas e, por meio destas, pudessem executar suas atividades adequadamente no trabalho, compreender expressões e mensagens escritas, obter mais oportunidades de emprego, entre outras atividades (KNOBEL \& LANKSHEAR, 2011).

Entretanto, os autores criticam o teor passivo e talvez submisso subjacente a essa noção de letramento funcional. Na voz dos autores: 


\title{
Dossiê Especial: Formação Docente, Tecnologias Digitais e Educação Crítica. \\ ROCHA; HIBARINO e AZZARI (orgs.) \\ Revista X, vol.2, 2015
}

\begin{abstract}
A essência de ser funcionalmente letrado envolve um estado passivo, orientado para a sobrevivência e, portanto, negativo. A pessoa que é funcionalmente letrada pode sobreviver; pode lidar com o mundo; pode conseguir preencher um formulário de entrevista de trabalho após ter lido um anúncio do trabalho; pode conseguir o emprego (talvez) e, tendo feito isso, pode sobreviver nesse emprego; pode localizar serviços médicos e de saúde em sua comunidade; pode ler os horários de ônibus, etc. Ser funcional é ser não incapaz de lidar - é essencialmente um estado negativo no sentido que representa nada que possa ser visto como produtivo, como uma expressão positiva da vida humana. Além disso, essa noção envolve um estado passivo, já que ser capaz de lidar eficientemente em um contexto cultural ou social é uma questão de compreender e seguir, não de comandar e liderar. (LANKSHEAR \& KNOBEL, 2011, p 7)
\end{abstract}

Ao estender essa discussão para contextos educacionais, o que pretendo frisar é que da mesma maneira que uma compreensão de escrita e leitura "para sobrevivência" parece enfraquecer o papel protagonista do aluno no mundo, relegando as práticas de leitura a atividades reprodutoras, essa visão também não contribui para o desenvolvimento do pensamento crítico dos aprendizes e da valorização de suas vozes, histórias e discursos, que, cabe a ressalva, são tão pertinentes quanto o fortalecimento de suas capacidades linguísticas.

Da mesma maneira, o ensino de leitura dissociado de seu impacto social tende a favorecer a formação de alunos mais complacentes ao que lhes é ensinado, aceitando os conhecimentos como "corretos" e, possivelmente, pouco cabíveis em contextos reais de uso da língua. A meu ver, não me parece ser esse o objetivo da educação voltada para a interculturalidade e criticidade (KAWACHI, 2015), de modo geral, e do ensino de línguas na atualidade, principalmente em face de tantos descompassos sociais e culturais para os quais, acredito, os aprendizes devem ser sensibilizados.

A esse respeito, Kalantzis e Cope (2012, p. 10) afirmam que um currículo fundamentado na passividade dos aprendizes não é apenas ineficaz diante dos objetivos gerais de uma educação visando a autonomia, mas também, possivelmente, incompatível com as expectativas dos próprios aprendizes. Para os autores: "Essa geração está mostrando sinais de frustração diante de um currículo de letramento antiquado que espera que eles sejam receptores passivos do conhecimento que supostamente é bom para eles" (KALANTZIS; COPE, 2012).

Isso significa que viabilizar práticas de linguagem que promovam a interação dos alunos como sujeitos ativos não está somente fundada na ideia de que a atuação 


\section{Dossiê Especial: Formação Docente, Tecnologias Digitais e Educação Crítica. ROCHA; HIBARINO e AZZARI (orgs.) \\ Revista X, vol.2, 2015}

protagonista é o que desejam professores e pesquisadores preocupados com uma educação mais crítica. A implementação de práticas pedagógicas que se baseiam na postura questionadora do aprendiz também se justifica pelo perfil dos próprios alunos das escolas e universidades atualmente: em geral, esses alunos interagem diariamente em redes sociais, em ferramentas de comunicação em dispositivos móveis, e em uma série de outros recursos tecnológicos nos quais a mera decodificação de textos não é suficiente. Nesses contextos, o jovem é constantemente motivado a produzir ao invés de reproduzir, a atuar ao invés de assistir, e esses novos papeis são contrários a currículos tradicionais que, como sugerem Kalantzis e Cope (2012), esperam que os alunos sejam receptores passivos de conhecimento, o que tende a frustrá-los e, assim, comprometer muitos dos objetivos pretendidos.

Um dos problemas do ensino fundamentado em exercícios de leitura "para sobrevivência", chamado por Cope e Kalantzis (2013, p. 117) de "ensino baseado em letramentos antigos", está na implicação de que língua e linguagem são construtos homogêneos, concepção problemática diante da natureza dialógica e situada da linguagem. Essa prática pedagógica promove um "catálogo de convenções de significados confinadas a uma forma padrão da língua escrita" (COPE; KALANZTIS, p. 117) o que é contrário à noção dinâmica de língua, linguagem e discurso que defendo aqui e que se estende para os sentidos situados do conceito de letramentos.

Além de revelar uma posição problemática de existência de uma "língua nacional homogênea", essa visão antiga de escrita é também excludente, pois coloca à margem todos aqueles que não se enquadram naquilo que se entende por "língua padrão".

A esse respeito, ainda em 1995, Kleiman já apontava que um dos objetivos dos estudos do letramento era, entre outras coisas, problematizar a questão do acesso a "grupos marginalizados que não conhecem a escrita" (KLEIMAN, 1995, p. 15). É simbólico e, ao mesmo tempo, sintomático perceber que há 20 anos, quando a palavra "letramento" ainda não estava dicionarizada, como afirma Kleiman (1995), a autora já criticava a exclusão de grupos cujas práticas de letramentos não são levadas em consideração em muitas instâncias sociais, entre elas a escola / universidade. Essa é uma constatação notável porque mesmo 20 anos atrás, a exclusão por meio da escrita já era evidente, e a situação parece, em muitos aspectos, a mesma hoje; talvez os processos de discriminação e marginalização tenham até se acentuado diante dos movimentos de 


\section{Dossiê Especial: Formação Docente, Tecnologias Digitais e Educação Crítica. ROCHA; HIBARINO e AZZARI (orgs.) \\ Revista X, vol.2, 2015}

globalização que encurtam distâncias mas que, ao mesmo tempo, escancaram e acentuam as diferenças (GARCIA CANCLINI, 2008).

É, também, uma observação sintomática porque, nos dias de hoje, a marginalização não se dá somente por meio da escrita em sua concepção tradicional. Em uma era de multissemioses e plurilinguismo, a exclusão e discriminação atingem aqueles que se expressam por meio de outras modalidades (grafite; rap; blogs) não contempladas nos currículos escolares, por exemplo. Estes, muitas vezes, privilegiam somente a modalidade escrita padrão - sem focalizar diferentes linguagens sociais e registros (GEE, 1999; 2011), contextos de produção, histórico social e cultural dos alunos, entre muitos outros fatores que interferem no impacto social do texto em sua constituição abrangente. Desconsiderar essas expressões de linguagem e, assim, determinadas práticas de letramentos é, também, excluir.

Mesmo considerando que o termo "letramentos" já faz parte do discurso escolar (KLEIMAN, 2005), estando presente, por exemplo, nos Parâmetros Curriculares Nacionais (PCNs) e Orientações Curriculares do Ensino Fundamental e Médio do Estado de São Paulo, tanto nas disciplinas de língua portuguesa como língua estrangeira (inglês), reitero a importância de que as orientações didático-pedagógicas desses documentos e de outros contextos educacionais pertinentes abordem os letramentos sob um viés plural, abarcando gêneros discursivos diversos e produtos culturais que possam ir além do cânone. Ecoando Kalantzis e Cope (2012), isso se torna ainda mais pertinente quando pensamos em práticas de ensino tradicionais, que tem um enfoque estritamente gramatical e normativo, tendendo a padronizar e homogeneizar sentidos por meio do ensino de convenções e regras gramaticais.

A hipótese da existência de uma língua homogênea atrelada a práticas de leitura tradicionais se mostra falha quando pensamos na diversidade de construções linguísticas, de dialetos, de sotaques, de registro, de discursos, de linguagens, de símbolos e semioses que constituem quaisquer expressões em uma língua. Nesse sentido, a língua é uma construção heterogênea e de natureza contextualizada, o que significa que os sentidos variam de acordo com as situações e se materializam em práticas discursivas igualmente múltiplas. Um ensino de línguas "uniforme" e monolíngue me parece, portanto, insustentável porque as práticas de letramento com as quais os alunos tem contato em suas diversas esferas de atuação são densamente plurilíngues. Sob o mesmo raciocínio e trazendo para a discussão o papel da língua 


\section{Dossiê Especial: Formação Docente, Tecnologias Digitais e Educação Crítica. ROCHA; HIBARINO e AZZARI (orgs.) \\ Revista X, vol.2, 2015}

inglesa nesse cenário, é difícil vislumbrar um ensino de inglês "padrão" porque, especialmente em contextos de globalização e intercâmbios interculturais, a língua inglesa não é uma, não é um conjunto pacífico de regras pré-determinadas: é múltipla.

Em estudos recentes, alguns autores (PENNYCOOK, 2012; RAJAGOPALAN, 2004; 2010; RIBEIRO DA SILVA, 2011) defendem a desmistificação da figura do "falante nativo ideal" ou "falante modelo", especialmente porque em um cenário de internacionalização e intercâmbios sociais, culturais e linguísticos intensos, estabelecer um falante como "ideal" significaria excluir variantes linguísticas e ignorar relações de poder que permeiam o uso da LI nos mais diversos contextos atualmente.

É nesse sentido que entendo o ensino de inglês como dialético e complexo, pois envolve questões de política, imperialismo, poder e negociação de sentidos em situações cada vez mais interculturais, fazendo-se necessário, em face do papel de língua mundial (RIBEIRO DA SILVA, 2011) atribuído a essa língua, refletir sobre abordagens pedagógicas que permitam ao aluno não somente compreender aspectos linguísticos mas também buscar justificativas para o entendimento dos jogos de poder estabelecidos por meio dessa língua, fortalecer o olhar crítico aos produtos culturais geralmente construídos e divulgados por meio dessa língua, entre outros processos que tem a língua inglesa no seu cerne.

Por isso, assim como Rocha (2012, p. 37), julgo coerente pensar o inglês de maneira crítica, problematizando noções monolíticas e apagadoras da diferença, concebendo-o como "parte de práticas sociais em que imperam a pluralidade de língua e culturas e em que circulam simultaneamente uma multiplicidade de sentidos".

No que diz respeito ao ensino de inglês, portanto, é importante que as práticas de letramento empregadas na sala de aula não focalizem somente uma modalidade de língua, especialmente porque uma concepção estanque de texto e conhecimentos unilaterais são incongruentes com os "conhecimentos e habilidades multi e transdisciplinares" demandados atualmente, em diversas esferas (social, profissional, cultural, pessoal), porque vivemos em uma "nova ordem social, em que há novas regras, novas lógicas e novas formas de interação" (MONTE MÓR, 2012, p 172).

Assim, o que significava "ser letrado" no passado não é mais o mesmo que se entende na atualidade. As mudanças sociais, notadamente atreladas à evolução tecnológica, tem impacto na maneira como entendemos, usamos e aprendemos uma 


\section{Dossiê Especial: Formação Docente, Tecnologias Digitais e Educação Crítica. \\ ROCHA; HIBARINO e AZZARI (orgs.) \\ Revista X, vol.2, 2015}

língua. Isso sinaliza a necessidade de teorias mais contemporâneas e condizentes com essa nova ordem social.

\section{ENTRE (MULTI)LETRAMENTOS: NOVA ERA, NOVAS PERSPECTIVAS}

Tomando como certo que passamos por movimentos de reconfigurações sociais, culturais e epistemológicas amplas como resultado, principalmente, do avanço em tecnologias e ferramentas de comunicação, evidencia-se a noção de que os usos que fazíamos de uma língua em práticas de escrita e leitura no passado não são exatamente os mesmos que vivenciamos atualmente. Se, anos atrás, as fontes de contato com a leitura se resumiam majoritariamente ao texto impresso (revistas, jornais, papel), o que se vê, nos dias de hoje, é um aumento de produções textuais desenvolvidas para meios digitais, uma vez que a divulgação de notícias, por exemplo, ocorre mais rapidamente e atinge um maior número de leitores nessas condições contemporâneas. Além disso, as fronteiras entre os gêneros textuais estão cada vez mais fluídas e opacas, o que significa que um site de compartilhamento de vídeos, por exemplo, pode ser usado por empresas comerciais para divulgar um produto; por grupos jornalísticos para apresentar reportagens; por artistas para divulgar uma nova canção; e, mais significativamente, por usuários que podem ter esses e outros objetivos por meio da publicação de um vídeo ou de um comentário.

Dessa forma, as necessidades de uso da língua requeridas nesse cenário e em muitos outros pertinentes à negociação de sentidos em meios digitais são muito diversas, exigindo tanto capacidades linguísticas que outrora não eram cogitadas quanto posicionamentos críticos e ativos em face da multiplicidade de sentidos que se constrói e se vê nas práticas de letramentos atuais. Essa conjuntura nos leva a reconhecer os efeitos dessa nova constituição social de uso da língua para a educação, sobretudo linguística, o que significa que, nas palavras de Rojo (2013, p. 21), "precisamos entender o quanto, no passado, nossas tradições de educação para o letramento foram extremamente restritivas, de maneira a ver o que os alunos precisarão no futuro além do que estamos lhes dando agora".

Essa reflexão nos leva, mais uma vez, a contestar ideias monolíticas de língua, assim como suposições homogeneizantes acerca da existência de uma "língua padrão 


\section{Dossiê Especial: Formação Docente, Tecnologias Digitais e Educação Crítica. ROCHA; HIBARINO e AZZARI (orgs.) \\ Revista X, vol.2, 2015}

ideal" ou "modelos idealizados de língua", as quais são problemáticas diante da natureza multifacetada da linguagem na era da "modernidade líquida". Tais hipóteses, como defende Rojo (2013), são questionáveis especialmente em face da mutissemiose de textos/enunciados com os quais nos deparamos diariamente e que nos levam a multiplicidade de significações.

É com base nesse raciocínio que me volto à ramificação do conceito de letramentos para multiletramentos, o qual busca contemplar diferentes maneiras de construir sentidos na pós-modernidade em meio à constituição cada vez mais multimodal da linguagem.

Os estudos dos multiletramentos foram impulsionados pelas publicações do Grupo de Nova Londres, formado por professores e pesquisadores que se reuniram em meados dos anos 90 para discutir questões relevantes sobre o ensino de letramentos em meio às mudanças que vinham ocorrendo já naquela época e impactando as maneiras como as pessoas usa(va)m a escrita e leitura para a prática social. Em 2000, com a publicação de "Multiliteracies" (COPE \& KALANTZIS, 2000), as reflexões dos membros do Grupo ganham relevância e passam a ser parte substancial da literatura de muitas áreas (principalmente Educação e Linguística Aplicada), representando, portanto, um desdobramento notável em relação à teoria de letramentos.

Colocada de maneira objetiva, a pedagogia dos multiletramentos surgiu diante de uma preocupação centrada em língua e educação (COPE \& KALANTZIS, 2000; 2013). O emprego do prefixo "multi" à já estabelecida ideia de "letramentos" serve ao propósito de entender e colocar em efeito práticas de linguagem com teor plural de língua e de modalidade. Os autores destacam que em toda a constituição da Pedagogia dos Multiletramentos, privilegiar a diversidade (portanto, aspectos multilíngues e multimodais) é fundamental diante da necessidade de se pensar em um ensino mais condizente às configurações sociais e culturais das sociedades e, sobretudo, das salas de aula.

Ao explicitar os princípios que nortearam o desenvolvimento da pedagogia dos multiletramentos, Cope e Kalanztis (2000) frisam a preocupação do Grupo em pensar nas constituições e desdobramentos de práticas de letramento para três esferas de atuação de um indivíduo: ambiente de trabalho, cidadania e vida pessoal. Nessa direção, os multiletramentos se materializam em práticas sociais que nos levam a configurações de trabalho transformadas, a diferentes maneiras de apropriação de espaços públicos e a 


\section{Dossiê Especial: Formação Docente, Tecnologias Digitais e Educação Crítica. ROCHA; HIBARINO e AZZARI (orgs.) \\ Revista X, vol.2, 2015}

distintos modos de expressão de aspectos pessoais e identitários (COPE \& KALANZTIS, 2013).

Ao pensarmos, então, na efetivação dos multiletramentos em práticas de linguagem multimodais nas esferas da cidadania e da vida pessoal (e nas relações travadas nesses âmbitos), saliento, mais uma vez, a relevância de se refletir sobre os modos com que o ensino de língua inglesa de enfoque dialógico, materializado em práticas de letramentos críticas, bem como a educação para a interculturalidade e criticidade de modo geral, podem contribuir.

Em relação à implementação da pedagogia dos multiletramentos em sala de aula, Cope e Kalantzis (2000) sugerem que o trabalho visando o fortalecimento dos letramentos dos alunos deve ocorrer em quatro fases: prática situada, instrução explícita, enquadramento crítico e prática transformada.

Com a finalidade de repensar essas fases em termos de atos pedagógicos mais facilmente reconhecíveis, Cope e Kalantzis (2013) revisitam sua teoria e propõem uma ressignificação de tais momentos, compreendendo-os como momentos de experimentar, conceituar, analisar e aplicar, respectivamente. Os autores destacam que tais processos não são fixos: há um movimento contínuo de idas e vindas entre eles. O quadro a seguir permite um olhar comparativo entre essas propostas.

\begin{tabular}{|c|c|}
\hline $\begin{array}{c}\text { Orientações pedagógicas } \\
\text { (Formulação de 1996) }\end{array}$ & $\begin{array}{l}\text { Processos de conhecimento } \\
\text { (Reformulação de 2006) }\end{array}$ \\
\hline Prática situada & $\begin{array}{l}\text { Experimentar } \\
\text {...o conhecido } \\
\text {...o novo }\end{array}$ \\
\hline Instrução explícita & $\begin{array}{l}\text { Conceituar } \\
\text {...por nomeação } \\
\text {...com teoria }\end{array}$ \\
\hline Enquadramento crítico & $\begin{array}{l}\text { Analisar } \\
\text {...funcionalmente } \\
\text {...criticamente }\end{array}$ \\
\hline Prática transformada & $\begin{array}{l}\text { Aplicar } \\
\text {...apropriadamente } \\
\text {...criativamente }\end{array}$ \\
\hline
\end{tabular}

Quadro - "A microdinâmica da pedagogia dos multiletramentos" - retirado de Cope e Kalantzis (2013, p. 128)

Na minha perspectiva, trata-se de uma tentativa de abordar um conceito abstrato e complexo (como também é a ideia de "letramentos") sob um viés prático e com um 


\section{Dossiê Especial: Formação Docente, Tecnologias Digitais e Educação Crítica. ROCHA; HIBARINO e AZZARI (orgs.) \\ Revista X, vol.2, 2015}

teor mais didático-pedagógico do que estritamente teórico, e isso merece ser destacado, afinal, o que se espera é que as discussões teóricas em torno dos multiletramentos possam ser implementadas na prática de sala de aula. No entanto, parece-me que ao supor a existência de quatro fases distintas no trabalho em direção à construção de letramentos múltiplos, pode haver a impressão de que o ensino de línguas ocorre em "níveis" rigidamente delimitados e com limites previamente estabelecidos. Ainda que os próprios autores esclareçam que essas fases não são lineares e, nesse sentido, não devem ser entendidas como "escada" de aprovação ou ascensão, ainda poderia haver a hipótese de que, mesmo não sendo lineares, essas fases sejam momentos fechados sem interrelações entre si, o que, a meu ver, não ocorre.

Entendo que, em sala de aula, na maioria das vezes o professor parte de algum conteúdo, tema ou proposta para lidar com metalinguagem, pensamento crítico, efeitos de sentido do texto para a prática social e implicações do contexto social para os sentidos do texto ao mesmo tempo em que busca, nesse processo, construir e estimular a prática dos alunos de maneira transformada. Na minha concepção, tudo isso parece ocorrer mais ou menos simultaneamente, de maneiras nem sempre claras e nítidas, pendendo sempre à noção do complexo.

Há de se considerar, também, que as muitas possibilidades de produção de sentido por meio da escrita em práticas multimodais na Internet podem representar problemas, quando, por exemplo, faz-se uso de espaços virtuais públicos (comentários em sites de compra, em sites de compartilhamento de vídeos e em redes sociais, por exemplo) para a expressão de discursos de ódio, de preconceito e de extremismos. Nesses casos, como explicam Recuero e Soares (2013), diversos tipos de violência simbólica emergem principalmente diante de um anonimato ou autoria mascarada que leva à expressão de discursos radicais. Isso evidencia, portanto, que apenas o acesso às tecnologias digitais não garante deslocamento discursivo: é preciso haver um trabalho sistemático de sensibilização em torno dos efeitos de nossas escolhas linguísticas e de suas ramificações em mídias de comunicação de alcances tão profundos.

É exatamente por isso que, simultaneamente ao desenvolvimento dos letramentos múltiplos dos estudantes a fim de prepará-los para o contato com textos cada vez mais multimodais, é preciso, também, educá-los para o fortalecimento de perspectivas críticas que os auxiliem a reconhecer, compreender e, principalmente, 


\section{Dossiê Especial: Formação Docente, Tecnologias Digitais e Educação Crítica. ROCHA; HIBARINO e AZZARI (orgs.) \\ Revista X, vol.2, 2015}

selecionar conteúdos e conhecimentos disponíveis em múltiplas ferramentas digitais e fontes de informação.

De acordo com Jenkins (2009), é importante que os alunos da era digital tenham uma visão crítica do potencial de representações midiáticas em interferir em nossas percepções de mundo. $\mathrm{O}$ autor defende a necessidade de uma compreensão crítica da mídia como uma das instituições sociais, políticas, culturais e econômicas mais poderosas de nossa época (JENKINS, 2009, p. 29).

Pensando, ainda, na constituição de sentidos de maneira multimodal, tem-se o exemplo de mashups, aplicações da internet que integram diversas fontes de sentido, incluindo textos tradicionais, imagens, mapas, localização do usuário em relação a um local específico, etc.

É notável, portanto, que na pedagogia dos multiletramentos, todas as formas de representação (o que inclui a língua) são dinâmicas e servem aos propósitos de construção, transformação, e não mais reprodução (COPE e KALANZTIS, 2013). Isso distancia claramente essa abordagem daquelas estruturalistas ou behavioristas, por exemplo, que tinham em procedimentos de repetição e reprodução uma de sua práticas pedagógicas mais recorrentes - o que não significa que não eram eficazes. Significa, na perspectiva aqui defendida, que são, em vários aspectos, conflitantes com a constituição social, cultural e epistemológica das relações (humanas, culturais, linguísticas) existentes atualmente.

No que se refere à atuação do professor de LI em sala de aula, essas teorizações são relevantes pois oferecem bases para que possamos investigar, se assim quisermos, quais letramentos são favorecidos em um ensino de inglês fundamentado na noção de língua como diálogo e amparado pela pedagogia dos multiletramentos.

Nesse cenário, destaco a necessidade de buscarmos potencializar letramentos diversos - e não apenas aqueles entendidos como estritamente curriculares ou canônicos - em um ensino de LI orientado por premissas críticas e de formação cidadã, visando o enfrentamento de conflitos e atuação frente a diferenças sociais e culturais. Em uma agência de letramentos como a universidade, é preciso viabilizar tentativas de se colocar em efeito, em primeiro lugar, práticas de linguagem adequadas ao contexto sóciohistórico contemporâneo que evidenciam a emergência de uma geração e cultura participatória (JENKINS, 2009), e, em seguida, investigar que práticas e discursos são mobilizados como reflexo de propostas pedagógicas mais contemporâneas. 


\section{Dossiê Especial: Formação Docente, Tecnologias Digitais e Educação Crítica. ROCHA; HIBARINO e AZZARI (orgs.) \\ Revista X, vol.2, 2015}

Trata-se, portanto, de direcionarmos nosso olhar às atividades que promovemos em sala de aula a fim de analisarmos se os conteúdos privilegiados dentro da escola e da universidade são condizentes com as práticas de linguagem que esses estudantes vivenciam diariamente, em um mundo cada vez mais marcado por extremismos, violência e intolerância para os quais nossos alunos devem ser sensibilizados em um processo de ensino-aprendizagem orientado para a interculturalidade e criticidade, como defendo.

\section{CONSIDERAÇÕES FINAIS}

No decorrer deste trabalho, procurei advogar a favor de concepções de ensinoaprendizagem e de língua mais condizentes com as configurações sociais, culturais e educacionais que vivenciamos atualmente. Isso se deve, principalmente, ao fato de que os problemas de uso de linguagem que emergem em nossas salas de aula podem ser abordados sob perspectivas mais questionadoras quando contemplamos práticas que possam ir além das estruturas linguísticas, em direção à sensibilização do aluno em torno de muitos entraves sociais que não podem, a meu ver, ser ignorados na prática pedagógica.

Isso significa, também, que é preciso pensarmos cada vez mais em maneiras de aproximarmos os universos de nossos alunos àquilo que efetivamente fazemos em sala de aula. Nessa direção, argumento a favor de um processo de ensino de língua inglesa marcado por preocupações sociais e linguísticas, perpassando foco na forma (aspectos linguísticos) ao mesmo tempo em que se privilegiam discussões sobre diferenças culturais, preconceito, machismo, homofobia, intolerância, ou seja: problemas sociais que, amparados por orientações teóricas e metodológicas apropriadas e críticas, podem contribuir para a formação ética e cidadã do aluno da era em que vivemos.

Com isso, acredito que as teorias de letramentos e sobretudo as teorizações sobre multiletramentos podem oferecer possibilidades de trabalho com língua, criticidade, interculturalidade, tecnologia e sociedade pautando-se em práticas que privilegiam a diversidade de linguagens e modalidades, portanto plurilíngues e multimodais. Isso seria importante para criar condições, em sala de aula, para a reflexão e desestabilização de discursos de intolerância, desrespeito e extremismo que parecem ser reproduzidos com frequência em ambientes digitais. Na mesma linha de raciocínio, trazer a 


\section{Dossiê Especial: Formação Docente, Tecnologias Digitais e Educação Crítica. ROCHA; HIBARINO e AZZARI (orgs.) \\ Revista X, vol.2, 2015}

tecnologia para a sala de aula também implicaria pensar nos múltiplos efeitos de sentidos que produzimos quando (re)produzimos certos discursos.

Essas são preocupações que, reforço, precisam ser consideradas em processos de ensino que se voltem à investigação e reflexão de problemas sociais amplos. É para a problematização dessas (e muitas outras) questões que as teorias aqui discutidas podem, a meu ver, contribuir, sempre considerando o desejo de desenvolvimento e formação de alunos ativos, críticos, provocadores e inquietos frente às desigualdades que se desenrolam à sua frente, sob o seu (e o nosso) olhar.

\section{REFERÊNCIAS BIBLIOGRÁFICAS}

COPE, B.; KALANTZIS, M. (Eds.). Multiliteracies: Literacy Learning and the Design of Social Futures. London: Routledge, 2000.

. Multiliteracies: New Literacies, New Learning. In: HAWKINS, M. R. (Org.). Framing Languages and Literacies: Socially Situated Views and Perspectives, New York: Routledge, Pp. 105-135, 2013.

FAIRCLOUGH, N. Discourse and social change. Cambridge: Polity Press, 1992.

Critical Discourse Analysis: the Critical Study of Language. Harlow: Longman, 2010.

FOCHZATO, M. A. S. Nós só conseguimos enxergar dessa maneira...: representações e formação de educadores. Tese (Doutorado em Linguística Aplicada) - Instituto de Estudos da Linguagem, Unicamp, Campinas, 2010

FREIRE, P. Pedagogia da autonomia: saberes necessário à prática educativa. 25 ed. São Paulo: Paz e Terra, 2002 [1996].

GARCIA CANCLINI, N. G. Culturas Híbridas: estratégias para entrar e sair da modernidade. 4. ed, 4 reimp. Tradução CINTRÃO, H.P.; LESSA, A.R. São Paulo: EDUSP, 2008.

GEE, J. P. An introduction to discourse analysis: theory and method. London: Routledge, 1999.

How to do discourse analysis: A toolkit. London: Routledge, 2011.

JENKINS, $\mathrm{H}$. Confronting the challenges of participatory culture - Media education for the 21st century. The MIT Press: Massachusetts Institute of Technology, 2009.

KALANTZIS, M.; COPE, B. Literacies. Cambridge: Cambridge University Press, 2012.

KAWACHI, G.J. Ensino de inglês para a interculturalidade: investigando práticas e representações discentes no ProFIS/Unicamp. Tese (Doutorado). Universidade Estadual de Campinas (Unicamp), 2015.

KEATING, A. Teaching transformation: transcultural classroom dialogues. New York: Palgrave MacMillan, 2007.

KLEIMAN, A. B. Modelos de letramentos e as práticas de alfabetização na escola. In: (Org.) Os significados do letramento: um nova perspectiva sobre a prática social da escrita. Campinas: Mercados de Letras, p. 15-64, 1995. 


\section{Dossiê Especial: Formação Docente, Tecnologias Digitais e Educação Crítica. ROCHA; HIBARINO e AZZARI (orgs.)}

Revista X, vol.2, 2015

. Preciso "ensinar" o letramento? Não basta ensinar a ler e escrever? Campinas: Cefiel - Unicamp; MEC, 2005.

KRESS, G. Design and transformation: new theories of meaning. In: COPE, B.; KALANTZIS, M. (Eds.) Multiliteracies: literacy learning and the design of social futures. London: Routledge, Pp. 153-161, 2000.

LANKSHEAR, C.; KNOBEL, M. Literacies: social, cultural and historical perspectives. New York: Peter Lang Publishing, 2011.

LUKE, A. Defining critical literacy. In: PANDYA, J.; AVILA, J. (Eds.). Moving critical literacies forward: a new look at praxis across contexts. New York: Routledge, Pp.19-31, 2014.

MAHER, T. M. A Educação do Entorno para a Interculturalidade e o Plurilinguismo. In: KLEIMAN, A. B.; CAVALCANTI, M. C. (Orgs.). Linguística Aplicada: faces e interfaces. Campinas, SP: Mercado de Letras, Pp. 255-270, 2007.

MONTE MÓR, W. Investigating critical literacy at the University in Brazil. In: MENEZES DE SOUZA, L. M.; ANDREOTTI, V. (Eds.). Critical Literacy: theories and practices. London, Pp. 41-51, 2007

Linguagem tecnológica e educação: em busca de práticas para uma formação crítica. In: SIGNORINI, I.; FIAD, R. S. (Org.) Ensino de Lingua: das reformas, das inquietações e dos desafios. Belo Horizonte: Editora UFMG, Pp.171-190, 2012.

Crítica e Letramentos Críticos: reflexões preliminares. In: ROCHA, C. H.; MACIEL, R. F. (Orgs.). Lingua estrangeira e formação cidadã: por entre discursos e práticas. Campinas: Pontes Editores, Pp. 31-59, 2013.

PENNYCOOK, A. Language and mobility: unexpected places. Bristol: Multilingual Matters, 2012.

RAJAGOPALAN, K. The Concept of "World English" and its Implication for ELT. In: ELT Journal. v. 58, n. 2, Oxford: Oxford University Press, Pp. 111-117, 2004.

The rigmarole of intelligibility in world english(es) - or, on making sense of it all or, if you like, making the very idea of intelligibility intelligible. Revista Letras \& Letras, v. 26, n. 2, Uberlândia, Pp. 477-492, 2010.

RECUERO, R; SOARES, P. Violência simbólica e redes sociais no facebook: o caso da fanpage "Diva Depressão". Galaxia (São Paulo, Online), n. 26, Pp. 239-254, 2013. Disponível em: $\quad<$ http://www.scielo.br/scielo.php?pid=S198225532013000300019\&script=sci_arttext $>$

RIBEIRO DA SILVA, E. O conceito de World Englishes em um livro didático de inglês utilizado na Escola Pública. Anais do SETA (UNICAMP), Pp. 280-291, 2011.

ROCHA, C. H. Reflexões e propostas sobre língua estrangeira no Ensino Fundamental I: plurilinguismo, multiletramentos e transculturalidade. Campinas: Pontes Editores, 2012.

ROJO, R. H. R. Letramentos Múltiplos: escola e inclusão social. São Paulo: Parábola, 2009.

Gêneros discursivos do Círculo de Bakhtin e multiletramentos. In: ROJO, R. H. R. (Org.) Escola conectada: os multiletramentos e as TICs. São Paulo: Parábola, Pp. 13-36, 2013. 